\title{
Accentuation of ichthyosis vulgaris due to associated leprosy
}

\author{
A. P. ShaH \\ M.D., D.V. \& D.
}

S. S. SHAH
M.D.

\begin{abstract}
Summary
A case of ichthyosis vulgaris associated with tuberculoid leprosy is reported. Ichthyotic scales were markedly accentuated within the anaesthetic patches of leprosy.

The probable mechanism of the accentuation of ichthyosis by leprosy is discussed.
\end{abstract}

THE word ichthyosis is derived from the Greek word Ichthys meaning a fish. Patients with ichthyosis exhibit prominent scales occurring more or less diffusely all over the body. Usually the scales are large and centrally adherent with loose edges. Ichthyosis is a disorder of keratinization. Ichthyosis forms a group of genodermatoses transmitted by autosomal dominant or, as recently shown by Wells \& Jennings (1967), as an X-linked recessive trait. Apart from being commonly associated with atopy, ichthyosis vulgaris is a manifestation of many syndromes, viz. Refsum's syndrome (Refsum, 1946; Refsum, Solomonsen \& Skatvedt, 1949), Sjögren-Larsson syndrome (Sjögren \& LarssCn, 1957), Sonneck syndrome (Sonneck, 1952), and Rud syndrome (Rud, 1927). Ichthyosis is also reported to be associated with mental deficiency (Laubenthal, 1939), acrofacial dysostosis (Korting \& Ruther, 1954), ectropion (Forsius, 1949), cataract (Pinkerton, 1958) and other eye defects (Taussig, 1939) and alopecia (Marzollo, 1936). We here present a case of ichthyosis vulgaris associated with leprosy. Such an association has not been reported in literature so far. However the development of ichthyosiform changes of the skin has been reported in cases of leprosy in Africa (Schulz, 1965). Interestingly, there was a marked increase in the ichthyotic scales in the anaesthetic patches of leprosy in the present case.

\section{Case report}

A 36-year-old Hindu female was admitted to the Irwin Group of Hospitals, Jamnagar, on 25 May 1972. She had had moderate ichthyosis vulgaris since early infancy. The disease used to worsen during winter and decrease during summer. According to her she had had tingling and numbness on both hands 7 years before. Later on she developed anaesthesia on both the hands. On several occasions she got superficial burns on the fingers while cooking. Her deceased parents had been normal and not suffered from any skin disease. One of her brothers out of six siblings had atopy and none had ichthyosis. One of her sons out of six children had keratosis of palms and soles.

On examination the patient had moderate ichthys osis on the neck, trunk, back and extremities. Alk the fingers of both the hands had tapered, witk atrophic shiny skin on the terminal phalanges. There was complete absence of all sensations on the terminal phalanges of the fingers and lateral aspect of both hands. The ulnar nerves were thickened on both sides. There were two well-defined irregular patches on the back (Fig. 1). Ichthyosis on both the patches was markedly accentuated. The ichthyotic scales within these areas were oval and obviously larger than those present elsewhere on the body (Fig. 1). Touch, pain and temperature sensations were absent over these patches. Systemic examination did not reveal any abnormality.

Investigations. WBC $8200 / \mathrm{mm}^{3}$, polymorphs $66 \%$, lymphocytes $30 \%$ and eosinophils $4 \%$. Hb $13 \mathrm{~g} / 100$ $\mathrm{ml}$ with normocytic, normochromic peripheral smear. ESR $37 \mathrm{~mm} / \mathrm{hr}$ (Wintrobe). Urine examination was negative. Chest skiagram was normal. Nasal smear for acid-fast bacilli was negative. Intradermal injection of $0.1 \mathrm{ml}$ of histamine in the leprosy patch resulted in a larger wheal and more rapid appearance of surrounding erythema than that of normal area. A scratch test with histamine produced a smaller surrounding area of erythema over the leprosy patch. Skin biopsies were obtained from the anaesthetic leprosy patch and from surrounding normal ichthyotic skin. Both the sections revealed marked hyperkeratosis, absence of the granular layer with atrophy of stratum malpighii and loss of 


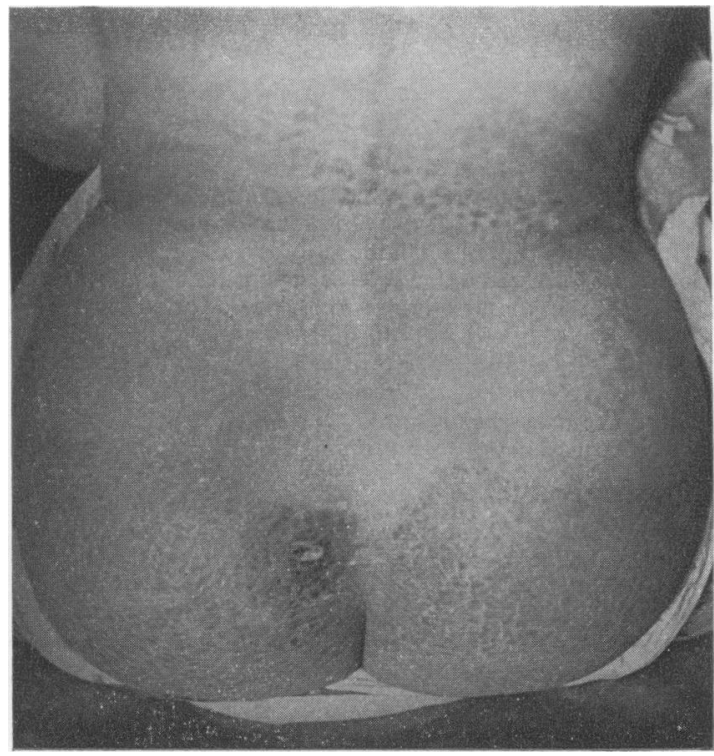

Fig. 1. Showing two leprosy patches with accentuated ichthyosis.

the rete ridges. In addition the changes of tuberculoid leprosy were seen in the section obtained from the anaesthetic patch.

\section{Discussion}

Leprosy is a fairly common condition in India. Its association with ichthyosis is not a matter of surprise but can be due to chance. Accentuation of ichthyosis in the leprosy patch has not been reported so far. However, Petrone (1969) reported a case in whom accentuation of ichthyosis was observed in a postoperative denervated area on the anterolateral aspect of the thigh. He studied stratum corneum turn-over time using a fluorescent dye (tetrachlorsalicylanilide) and observed that there was marked increased scale adherence in the denervated area and there was marked increase in epidermal turnover time. Accentuation of ichthyosis in the present case in leprosy patches could be due to denervation. Denervation in the patch was present clinically and was confirmed by the histamine test.

\section{Acknowledgments}

We are grateful to Dr H. H. Shah, Dean, Shri M. P. Shah Medical College and Irwin Group of Hospitals, Jamnagar for giving us the permission to publish this paper. We are also thankful to Mr R. M. Pandya, college photo artist, for his valuable help.

\section{References}

Forsius, H. (1949) Ectropion operations in icththyosis congenita. Acta ophthalmologica, 27, 573.

KoRTING, G.W. \& Ruther, H. (1954) Ichthyosis Vulgaris und Acrofaciale Dysostose. Archives of Dermatology and Syphilology, 197, 91.

Laubenthal, F. (1939) Uber den Erokreis der Ichthyosis Vulgaris. Archives of Dermatology and Syphilology, 179, 675.

Marzollo, E. (1936) Ichthyosis vulgaris and alopecia. Archives of Dermatology and Syphilology, 174, 171.

Petrone, G.S. (1969) Accentuation of ichthyosis vulgaris in denervated skin. Archives of Dermatology, 100, 423.

PINKERTON, O.D. (1958) Cataract associated with congenital ichthyosis. Archives of Ophthalmology, 60, 392.

RefSUM, S. (1946) Heredopathia atactica polyneuritiformis. Acta psychologica scandinavica, Suppl. 38.

Refsum, S., Solomonsen, L. \& Skatvedt, M. (1949) Heredopathia atactica polyneuritiformis in children. Journal of Paediatrics, 35, 335.

Rud, E. (1927) Et Tilfaelde of Infantilisme med Tetani, Epilepsi, Polyneuritis, ichthyosis og Anaemi af Pernicios type. Hospitalstidende, 70, 525.

SchULz, E.J. (1965) Ichthyosiform conditions occurring in leprosy. British Journal of Dermatology, 77, 151.

SJogren, T. \& LaRsSON, T. (1957) Oligophrenia in combination with congenital ichthyosis and spastic disorder. Acta psychologica scandinavica, 32, Suppl. 113, 1.

SoNNECK, H.G. (1952) Uber gleichzeitigs Vorkommen von Ichthyosis und Kryptorchismus. Dermatologische Wochenschrift, 126, 662 .

TAussig, L. (1939) Ichthyosis with involvement of cornea. Archives of Dermatology and Syphilology, 40, 504.

Wells, R.S. \& JenNingS, M.C. (1967) X-linked ichthyosis and ichthyosis vulgaris. Journal of the American Medical Association, 202, 485. 